\title{
Experimental investigation and hygrothermal modelling of freeze-thaw process of saturated fired clay materials including supercooling phenomenon
}

\author{
Kazuma Fukui ${ }^{1, *}$, Chiemi Iba $^{1}$, Madoka Taniguchi ${ }^{2}$, Kouichi Takahashi $^{2}$, and Daisuke Ogura ${ }^{1}$ \\ ${ }^{1}$ Kyoto University, Graduate School of Engineering, 615-8540 Kyoto, Japan \\ ${ }^{2}$ Hokaido Research Organization, Building Research Department, 078-8801 Asahikawa, Japan
}

\begin{abstract}
To investigate the supercooling phenomenon in fired clay materials, low-temperature differential scanning calorimetry (DSC) and a one-dimensional freeze-thaw (FT) experiment were performed on saturated specimens. The rate of increase in ice saturation during freezing was calculated from the DSC result. Rapid ice growth over a relatively narrow temperature range (within about $0.2 \mathrm{~K}$ ) was observed at a cooling rate of $0.25 \mathrm{~K} / \mathrm{min}$. In the FT experiment, the temperature distribution of a specimen was measured with inserted thermocouples. According to the results of the FT experiment, a rapid temperature increase was observed at sub-zero temperatures accompanied by freezing of the supercooled water. When the supercooled water began to freeze, the released latent heat was found to strongly prevent the specimen temperature from dropping even during the cooling period. Finally, a hygrothermal model of freezing and thawing including a non-equilibrium supercooling process was developed. The freezing rate of the supercooled water was modelled based on the DSC result. The validity of the model was verified by comparing the results of the FT experiment and calculations. The model was found to be able to replicate the rapid temperature rise during the cooling period of the FT experiment.
\end{abstract}

\section{Introduction}

Freezing of porous building materials is one of the main causes of the deterioration in cold environments. Investigating the causes of deterioration, choosing the suitable building materials and proposing effective building construction and repair methods require accurately predicting the risk of frost damage under various environmental conditions. For this purpose, numerical models were developed in many studies to analyse the thermal and/or moisture behaviours including freezing and thawing $[1,2]$. Some others have also described mechanical behaviour [3, 4].

The freezing point depression of water in porous materials can be expected from the pore radius assuming thermodynamic equilibrium [5]. However, water is known to remain in a non-equilibrium liquid state even below the equilibrium freezing point, which is called supercooling phenomenon. When the supercooled water starts freezing, solidification occurs much more rapidly than that without the supercooling effect. This rapid ice growth has a significant effect on the hygrothermal and mechanical behaviours of the material. During freezing of the supercooled water, a sharp rise in temperature and expansion of the material were observed [6].

Several researchers have used numerical simulations to investigate the effects of supercooling on the hygrothermal and mechanical behaviours of porous building materials. Zeng et al. [7] examined the supercooling phenomena in their poromechanical model, assuming that the freezing was delayed to lower temperature than the equilibrium freezing point. They calculated the freezing expansions and the results reasonably agreed with the experimental results. They also investigated the relationship between the extent of supercooling and expansion during freezing [8]. Gawin et al. [9] developed a hygrothermal model that includes the hysteresis of the ice content and the supercooling effects.

However, the models in these studies were validated with experimental results using small specimens, in which temperature and moisture distribution was expected to be small. In addition, although most of these investigations have been performed on cement-based materials, other building materials such as fired clay materials are also known to be affected by the supercooling effect. Rapid temperature rises have been observed in both laboratory experiments and outdoor environments [10,11]. Because of large differences in pore structures, supercooling of fired clay materials may have different characteristics compared to cement-based materials.

In this study, we have conducted low-temperature differential scanning calorimetry (DSC) and a freezethaw (FT) experiment on saturated fired clay materials to obtain information on supercooling, such as the freezing point of supercooled water, the rate of ice saturation

* Corresponding author: be.fukui-k1820@archi.kyoto-u.ac.jp 
increase and the rapid temperature rise during freezing. In the FT experiment, we measured the one-dimensional temperature distribution of the specimen. Then, a hygrothermal model of freezing and thawing was developed, including a non-equilibrium supercooling process based on the DSC result. Finally, the validity of the model was verified by comparing the results of the FT experiment with the calculated results.

\section{Material and methods}

\subsection{Material}

Clay produced in Aichi Prefecture, Japan, was sintered at $1000{ }^{\circ} \mathrm{C}$ to prepare the specimens used in this study. The clay is commonly used in the production of roof tiles in the area. The dry density and water content at vacuum saturation of the material were determined to be $1800\left[\mathrm{~kg} / \mathrm{m}^{3}\right]$ and $0.299\left[\mathrm{~m}^{3} / \mathrm{m}^{3}\right]$, respectively. Figure 1 shows the logarithmic differential pore volume distribution measured using mercury intrusion porosimetry. The material contained pores with relatively large diameters compared to cement-based materials $[12,13]$. Therefore, it is expected that most of the absorbed water is subject to lower pressure in the pores and the freezing point depression is small [5].

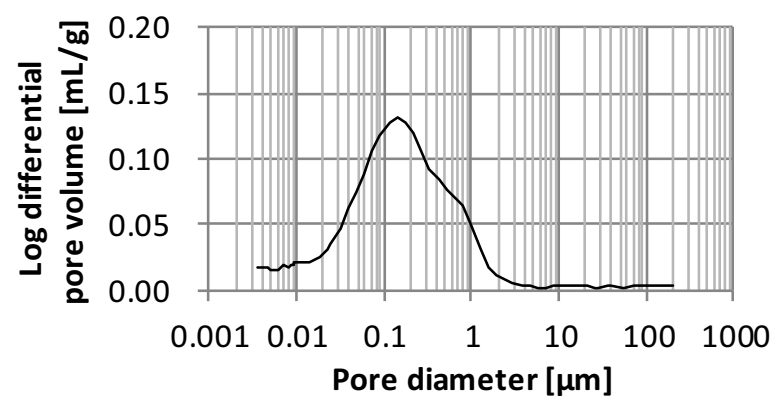

Fig. 1. Pore volume distribution of the fired clay material

\subsection{Differential scanning calorimetry (DSC)}

A DSC test was performed to determine the rate of heat release during freezing of the supercooled water. The result was used to model the rate of increase of ice content in the hygrothermal simulation.

We employed the DSC6200 made by Seiko Instruments Inc. Some of the material was broken into small pieces and saturated with water in a vacuum chamber. The measurement was performed on a specimen weighing $8.48 \mathrm{mg}$ in the dry state. The specimen is considered to be large enough to cover the range of the pore size contained in the material. The temperature of the specimen decreased from 25 to $-20{ }^{\circ} \mathrm{C}$ at a rate of $0.25[\mathrm{~K} / \mathrm{min}$. $]$. Heat flow from the specimen to the DSC device was recorded every second during the measurement. Note that the DSC was performed using other specimens at various cooling rates before the measurement reported in this paper. It was confirmed that no exothermic peak was observed below $-20{ }^{\circ} \mathrm{C}$ (in the range of -60 to $-20{ }^{\circ} \mathrm{C}$ ) and the resulting curve reported in this paper showed the same trend as the other results.

Equation (1) shows the relationship between the rate of the ice saturation increase and the heat flow:

$$
m_{s} \phi \frac{\rho_{i}}{\rho_{s}} \frac{d \alpha}{d t}=\frac{1}{H_{l i}} \frac{d Q}{d t}
$$

where $H_{l i}$ is the latent heat of solidification $[\mathrm{J} / \mathrm{kg}], m_{s}$ is the mass of the specimen [kg], $t$ is time [s], $\alpha$ is the ice saturation, $\phi$ is the porosity and $\rho_{i}$ and $\rho_{s}$ are the density of the ice and specimen $\left[\mathrm{kg} / \mathrm{m}^{3}\right]$, respectively. $d Q / d t$ represents the heat flow [W], where $Q$ is the amount of heat of the specimen [J]. The general kinetic equation (2) [14] was used to model the rate of ice saturation increase $(d \alpha / d t)$ :

$$
\frac{d \alpha}{d t}=A \exp \left(-\frac{E}{R T}\right) f(\alpha)
$$

where $A$ is a constant $\left[\mathrm{s}^{-1}\right], E$ is activation energy [ $\left.\mathrm{J} / \mathrm{mol}\right]$, $f(\alpha)$ is a function of ice saturation $\left(=\alpha^{b}(1-\alpha)^{c}\right.$, where $b$ and $c$ are constants $), R$ is the gas constant $[\mathrm{J} /(\mathrm{K} \cdot \mathrm{mol})]$ and $T$ is the temperature $[\mathrm{K}]$. With reference to the literature [15], the values of $A, E, m$ and $n$ were determined to fit the evolution of ice saturation obtained from equation (1).

\subsection{Freeze-thaw experiment}

Figures 2 and 3 show the schematic views of the test chamber and the cross section of the specimen, respectively. The specimen was a rectangle with a bottom surface of $21.0 \mathrm{~mm} \times 45.3 \mathrm{~mm}$ and a height of $96.5 \mathrm{~mm}$.

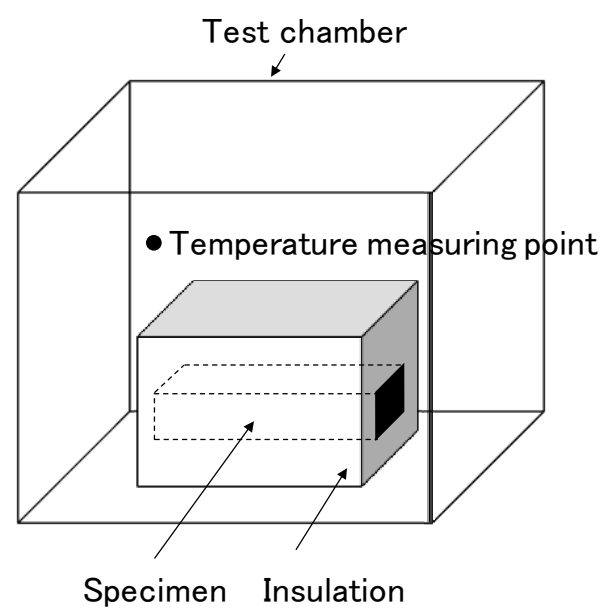

Fig. 2. Schematic diagram of the test chamber of the freeze-thaw experiment

One of the $21.0 \mathrm{~mm} \times 96.5 \mathrm{~mm}$ sides of the specimen was drilled with a $3 \mathrm{~mm}$ diameter drill. Then, thermocouples were inserted to the centre of the 21.0 $\mathrm{mm} \times 45.3 \mathrm{~mm}$ cross sections (points 2 to 6 in Fig. 3) 
The thermocouples were located at $15 \mathrm{~mm}$ intervals along the direction of the $96.5 \mathrm{~mm}$ sides. Measurement point 4 was located at the centre of the specimen. After inserting the thermocouples, epoxy resin was embedded in the holes. Thermocouples were also attached to the two bottoms with adhesive tapes (points 1 and 7 in Fig. 3).

The sides of the specimen were sealed with epoxy resin and covered with phenolic foam insulation to achieve one-dimensional heat transfer. The thickness of the insulation was more than $40 \mathrm{~mm}$. The specimen was saturated in a vacuum chamber before the experiment and the two bottoms were covered with plastic wrap to prevent evaporation.

The air temperature in the test chamber was controlled, as shown in Fig. 4. The maximum and minimum temperatures were set to 20 and $-10{ }^{\circ} \mathrm{C}$, respectively, and the temperature change was controlled at $0.25 \mathrm{~K} / \mathrm{min}$. The experiment involved four FT cycles. The cooling and heating periods were set at $6 \mathrm{~h}$ in the first two cycles. However, during the $6 \mathrm{~h}$ cooling period, the temperature could not reach the minimum and the cooling and heating periods were changed to $12 \mathrm{~h}$ in the remaining two cycles.

The specimen and test chamber temperatures were recorded every second during the experiment.

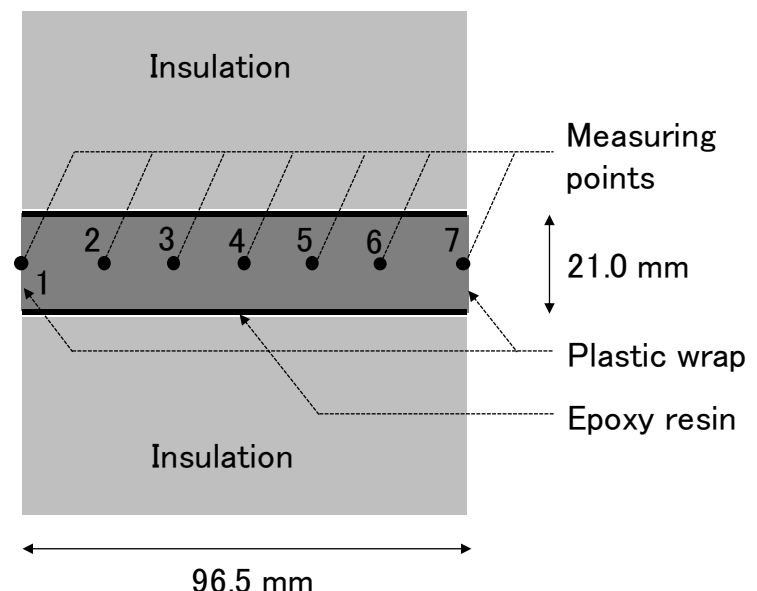

Fig. 3. Schematic diagram of the cross section of the specimen used for the freeze-thaw experiment

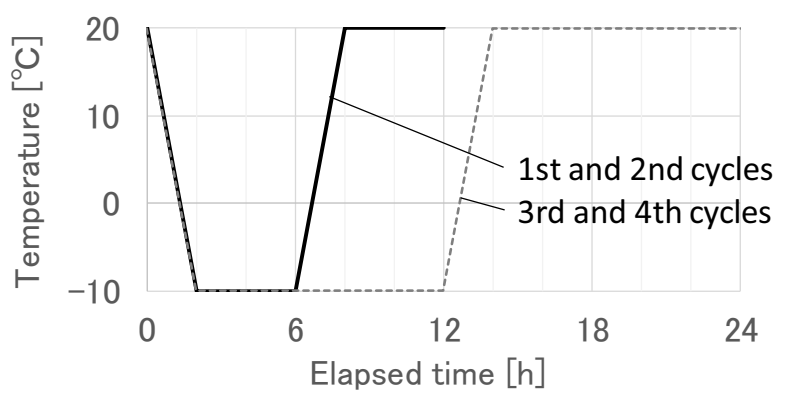

Fig. 4. Temperature control during the freeze-thaw experiment

\subsection{Hygrothermal modelling}

\subsubsection{Basic equations}

The following equations were used as the basic equations for heat and moisture transfer during freezing and thawing without supercooling $[1,16]$ :

$$
\begin{gathered}
c \rho \psi \frac{\partial T}{\partial t}=\nabla(\lambda \nabla T)+H_{v l}\left[\nabla\left(\lambda_{T_{T V}} \nabla T+\lambda^{\prime}{ }_{\mu \nu} \nabla \mu\right)\right] \\
+H_{l i} \frac{\partial \rho_{i} \psi_{i}}{\partial t} \\
\rho_{l} \frac{\partial \psi_{l}}{\partial \mu} \frac{\partial \mu}{\partial t}=\nabla\left[\lambda_{T^{\prime}} \nabla T+\left(\lambda^{\prime}{ }_{\mu \nu}+\lambda^{\prime}{ }_{\mu l}\right) \nabla \mu\right] \\
-\frac{\partial \rho_{i} \psi_{i}}{\partial t} \\
\mu=H_{l i} \ln \left(T / T_{0}\right) \simeq H_{l i}\left(T / T_{0}-1\right)
\end{gathered}
$$

where $c \rho \psi$ is the volumetric specific heat of wet material $\left[\mathrm{J} /\left(\mathrm{m}^{3} \cdot \mathrm{K}\right)\right], H_{v l}$ is the latent heat of vaporization $[\mathrm{J} / \mathrm{kg}], T_{0}$ is the melting point of bulk water $[\mathrm{K}], \lambda$ is the thermal conductivity $[\mathrm{W} /(\mathrm{m} \cdot \mathrm{K})], \lambda^{\prime}{ }_{T}$ is the moisture conductivity related to temperature gradient $[\mathrm{kg} /(\mathrm{m} \cdot \mathrm{s} \cdot \mathrm{K})], \lambda^{\prime}{ }_{\mu}$ is the moisture conductivity related to moisture chemical potential gradient $[\mathrm{kg} /\{\mathrm{m} \cdot \mathrm{s}(\mathrm{J} / \mathrm{kg})\}], \mu$ is the moisture chemical potential for free water $[\mathrm{J} / \mathrm{kg}], \rho$ is the density and $\psi$ is the volume fraction $\left[\mathrm{m}^{3} / \mathrm{m}^{3}\right]$. The subscripts $i, l$ and $v$ represent ice, liquid water and water vapor, respectively. Equation (5) was derived from the Clausius-Clapeyron equation for predicting freezing point depression. This equation shows that the $\mu$ of liquid water is uniquely determined by $T$ under thermodynamic equilibrium conditions. The approximate expression is also shown in equation (5). The difference between the original and the approximate expression is small above $-20^{\circ} \mathrm{C}[17]$.

The increase in volume due to the solidification forces unfrozen water to move toward the surfaces. However, the flow rate of water appears to be relatively small compared to the total amount of water in the saturated material. Therefore, $\lambda^{\prime}{ }_{T}$ and $\lambda^{\prime}{ }_{\mu}$ were ignored in the calculation.

Depending on the water state of the material, two or three equations from equations (3) to (5) were used to simulate the two-phase, non-equilibrium three-phase and equilibrium three-phase systems.

In the two-phase system, there is only water vapor and liquid water in the pores. Therefore, the terms for changes in ice mass $\left(\partial \rho_{i} \psi_{i} / \partial t\right)$ in equations (3) and (4) were ignored. In addition, as mentioned earlier, the flow of water in the material was ignored in this calculation. Therefore, equation (6) was used as the basic equation:

$$
c \rho \psi \frac{\partial T}{\partial t}=\nabla(\lambda \nabla T)
$$


In this model, crystallization does not start even if the temperature of the material falls a little below the equilibrium freezing point during the cooling period. When the temperature reaches the freezing point of the supercooled water, the water begins to freeze. In addition, the solidification of the supercooled water starts almost at the same time in a specimen [6]. Therefore, when a segment comes into contact with a segment containing ice, the segment also begins to freeze. The method of solidifying supercooled water in numerical simulations has also been used in a study simulating the solidification and melting processes of phase change materials [18].

For the non-equilibrium three-phase system, the final set of basic equations can be written as equations (7) and (8):

$$
\begin{gathered}
c \rho \psi \frac{\partial T}{\partial t}=\nabla(\lambda \nabla T)+H_{l i} \frac{\partial \rho_{i} \psi_{i}}{\partial t} \\
\rho_{l} \frac{\partial \psi_{l}}{\partial \mu} \frac{\partial \mu}{\partial t}=-\frac{\partial \rho_{i} \psi_{i}}{\partial t}
\end{gathered}
$$

The ice content increase rate $\left(\partial \psi_{i} / \partial t\right)$ in equations (7) and (8) is given in equation (9) using the parameters calibrated from the DSC result. This is derived from equation (2) using the relationship $\psi_{i}=\phi \alpha$ :

$$
\frac{d \psi_{i}}{d t}=\phi A \exp \left(-\frac{E}{R T}\right) f(\alpha)
$$

When the ice content reaches the equilibrium value, the state of water changes to the equilibrium three-phase system. In this system, all the three equations were used.

$$
\begin{gathered}
c \rho \psi \frac{\partial T}{\partial t}=\nabla(\lambda \nabla T)+H_{l i} \frac{\partial \rho_{i} \psi_{i}}{\partial t} \\
\rho_{l} \frac{\partial \psi_{l}}{\partial \mu} \frac{\partial \mu}{\partial t}=-\frac{\partial \rho_{i} \psi_{i}}{\partial t} \\
\mu=H_{l i}\left(T / T_{0}-1\right)
\end{gathered}
$$

During the heating period, when the temperature reaches the equilibrium freezing point, the water state changes directly from the equilibrium three-phase system to the two-phase system.

\subsubsection{Calculation model and conditions}

Figure 5 shows the calculation model. The calculation was performed in one dimension in the direction perpendicular to the bottom surfaces. The finite difference method was used. The basic equations are discretised by the central difference for space and the forward difference for time. The time and space steps were set to $0.004 \mathrm{sec}$ and $1 \mathrm{~mm}$, respectively. The calculation model contains 97 segments.

The initial temperature of the material was set to the average of the temperatures measured at the beginning of the FT cycle. Although the specimen was completely saturated at the beginning of the experiment, the initial water chemical potential of the specimen was set to -1 $[\mathrm{J} / \mathrm{kg}]$ to stabilize the calculation. Heat flow through the specimen surfaces was calculated using the Robin boundary condition at the temperature measured in the test chamber. The heat transfer coefficient between the surfaces and the air was set to $33\left[\mathrm{~W} /\left(\mathrm{m}^{2} \cdot \mathrm{K}\right)\right]$. Since the surfaces were covered with plastic wrap, moisture transfer through the surfaces was not considered.

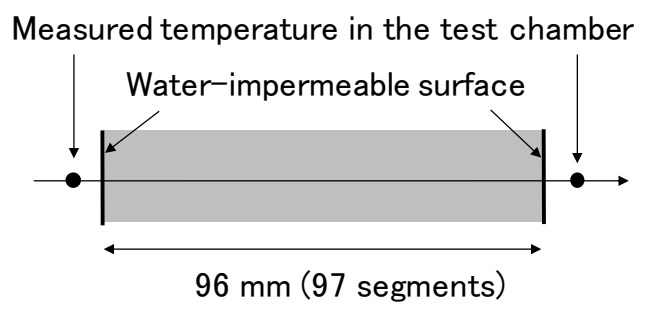

Fig. 5. Calculation model and boundary conditions

\subsubsection{Material properties}

The material properties used in the calculation were mainly derived from the previous study [19]. The dry density of the material and $\psi_{l}$ at vacuum saturation were set to $1800\left[\mathrm{~kg} / \mathrm{m}^{3}\right]$ and $0.299\left[\mathrm{~m}^{3} / \mathrm{m}^{3}\right]$, respectively.

The models in the literature $[1,16]$ use the same adsorption isotherm for both two-phase and three-phase systems. Therefore, when $T$ is given, $\psi_{l}$ is uniquely determined using equation (5) and the adsorption isotherm during the freezing and thawing process. The adsorption isotherm in the low humidity region was obtained from the gas absorption measurements [19]. Due to the lack of data in the high humidity region, the extent of capillary condensation was estimated from the pore volume distribution shown in Fig. 1 using the Kelvin equation (13):

$$
\ln (\phi)=\frac{2 \gamma V}{r R T}
$$

where $r$ is the pore radius [m], $V$ is the molar volume of water $\left[\mathrm{m}^{3} / \mathrm{mol}\right], \phi$ is the relative humidity and $\gamma$ is the surface tension of water $[\mathrm{N} / \mathrm{m}]$. Figure 6 compares the adsorption isotherm derived from the pore volume distribution with the gas adsorption method. In Figure 6, $\phi$ is converted to $\mu$ using equation (14):

$$
\mu=R_{v} T \ln (\phi)
$$

where $R_{v}$ is the specific gas constant of water vapor $[\mathrm{J} /(\mathrm{kg} \cdot \mathrm{K})]$. The curve obtained from the pore volume distribution suggests that $\psi_{l}$ varies between about -100 and $-10000[\mathrm{~J} / \mathrm{kg}]$. An adsorption isotherm curve model was created so that $\psi_{l}$ increased in the same range. The adsorption isotherm curve was also fitted to the results of the gas absorption measurement in the low humidity range. $\psi_{l}$ hysteresis was not considered in the calculation. 
The $\lambda$ of the material in air-dried and wet states with a water content of $0.271\left[\mathrm{~m}^{3} / \mathrm{m}^{3}\right]$ was 0.55 and 1.69 $[\mathrm{W} /(\mathrm{m} \cdot \mathrm{K})]$, respectively [19]. Equation (15) shows the linear function of water content generated from these two data:

$$
\lambda=4.21 \psi_{l}+0.55
$$

Equation (16) was used to apply equation (15) to the freezing and thawing processes:

$$
\lambda=4.21\left(\psi_{l}+\frac{\lambda_{i}}{\lambda_{l}} \psi_{i}\right)+0.55
$$

The specific heat capacity of the dry material was obtained from the literature [20], since no measurements were conducted in the previous study [19]. A brick value of $840[\mathrm{~J} /(\mathrm{kg} \cdot \mathrm{K})]$ was used.

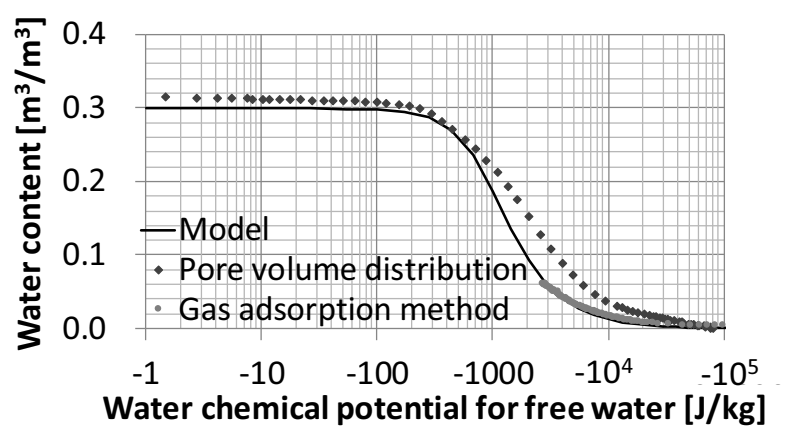

Fig. 6. Adsorption isotherm derived from the measurements and the model used in the calculation

\section{Results}

\subsection{Differential scanning calorimetry (DSC)}

Figure 7 shows the DSC result. Heat flow was only shown in the temperature range of -11 to $-8{ }^{\circ} \mathrm{C}$, as no large heat flow due to freezing was observed in other temperature ranges. The water froze in a narrow temperature range within about $0.2 \mathrm{~K}$. As shown in Fig. 8, the evolution of ice saturation was obtained from equation (1), and the parameters of equation (2) were calibrated based on the results. The calibrated parameters are as follows: $A=2.03 \times 10^{-14}\left[\mathrm{~s}^{-1}\right], E=-66050[\mathrm{~J} / \mathrm{mol}]$, $b=0.77$ and $c=1.29$.

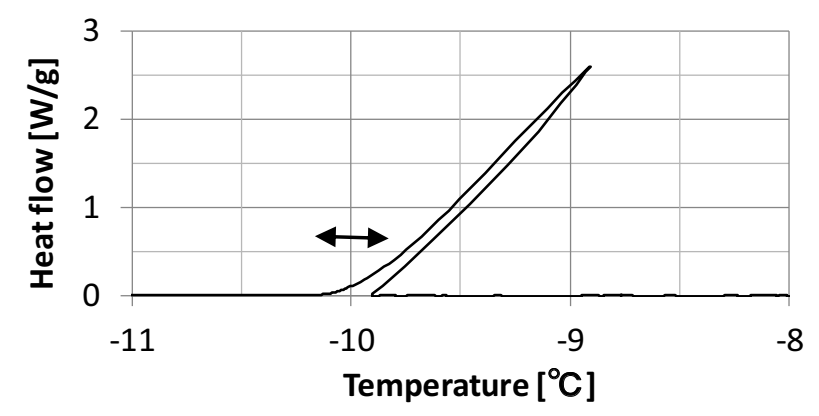

Fig. 7. Result of differential scanning calorimetry

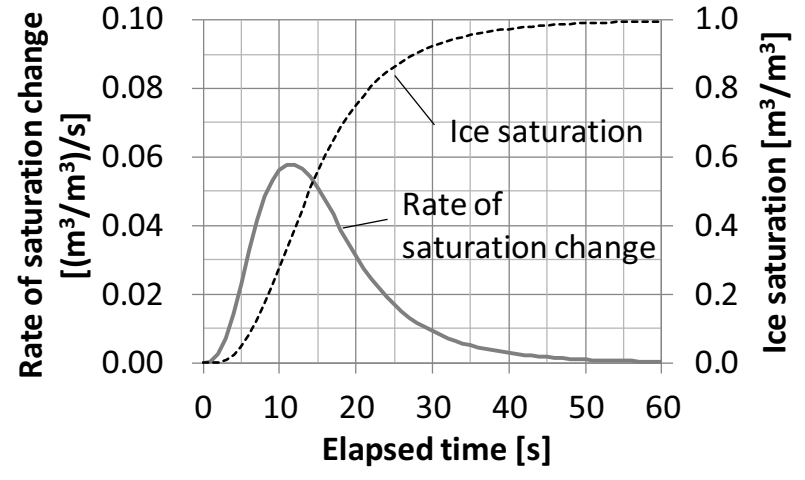

Fig. 8. Ice saturation evolution as a function of time

\subsection{Freeze-thaw experiment}

Figure 9 shows the temperature measurement results for the third and fourth FT cycles. The measured temperatures were symmetric, and the results only at measurement points 1, 2 and 4 are shown in Fig. 9 for simplicity. When the surface temperature of the specimen reached approximately $-5{ }^{\circ} \mathrm{C}$, the temperature of all measuring points rose rapidly due to the freezing of the supercooled water. When ice nucleation began, the released latent heat strongly hindered the cooling of the specimen.

The freezing point of supercooled water is known to be random [21]. In the experiment, the freezing point on the surface for the first FT cycle was $-3.90^{\circ} \mathrm{C}$, but the values for the second to fourth cycles were in a relatively narrow range $\left(-5.13 \pm 0.10{ }^{\circ} \mathrm{C}\right)$. The reason for different freezing points between cycles needs to be investigated to more accurately predict the hygrothermal behaviour during the supercooling process. However, in the calculation, the value was set to $-5.15{ }^{\circ} \mathrm{C}$, which was observed in the third FT cycle.

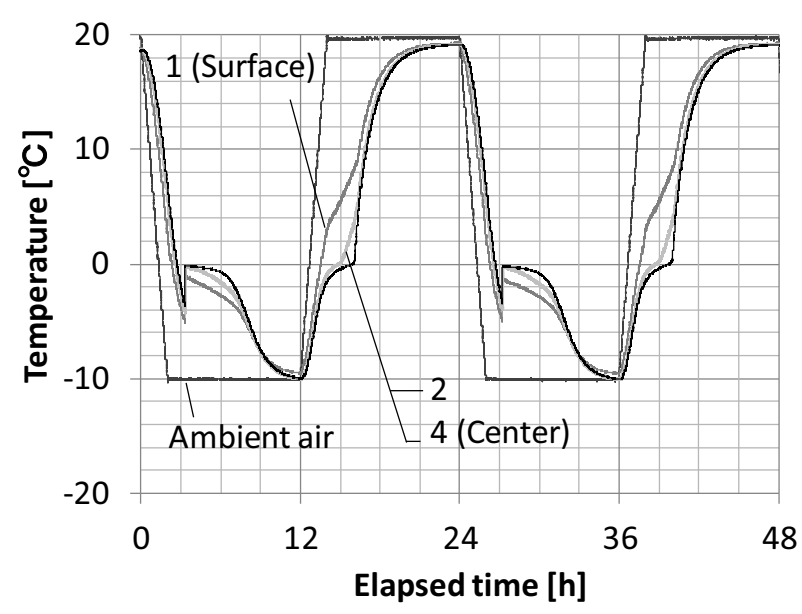

Fig. 9. Results of the temperature measurements in the third and fourth freeze-thaw cycles 


\subsection{Numerical analysis}

First, the calculation results without the supercooling process were compared with the experimental results in Fig. 10. Only the third FT cycle is shown because there is no significant difference between the calculation results of the third and fourth cycles. In addition, the results during the thawing process are very similar to those of the model including the supercooling process (see Fig. 11) and are not shown in Fig. 10. In this calculation, equations (3) to (5) were used throughout the freezing and thawing process $[1,16]$. The calculation and experimental results during the supercooling process do not match.

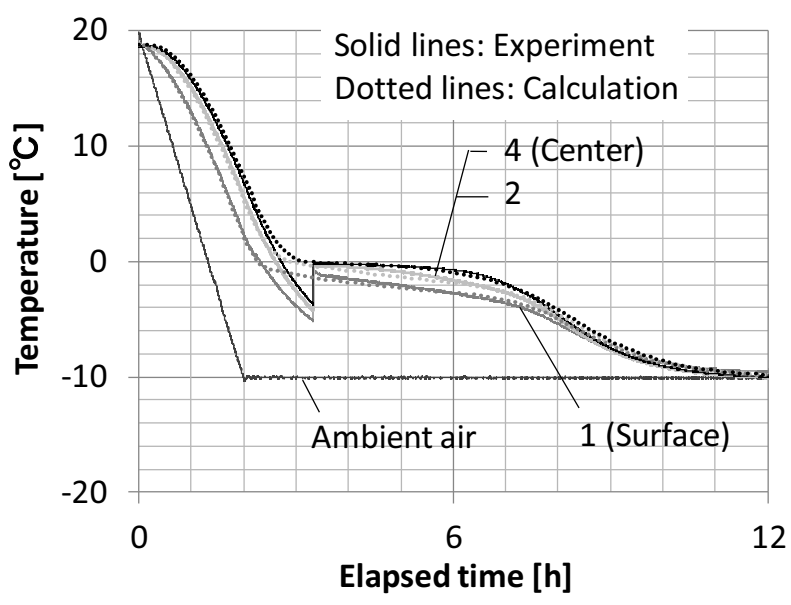

Fig. 10. Comparison of measured and calculated temperatures using a model without supercooling process

Figure 11 shows the calculation results using a model that includes supercooling. Figure 12 also shows an enlarged view around the elapsed time of $3.33 \mathrm{~h}$, when the temperature rapidly increased due to the freezing of the supercooled water. The calculation results in Fig. 11 adequately reproduce the supercooling process and rapid temperature rise observed in the FT experiment.

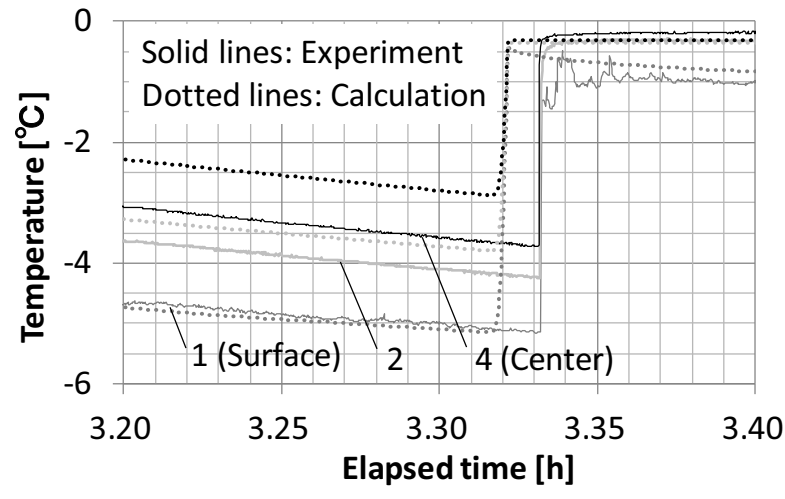

Fig. 12. Detailed comparison of measured and calculated temperatures during freezing of the supercooled water.

\section{Discussions}

Based on the DSC result obtained from the literature [22], the hardened cement pastes present broad and low exothermic peaks. In addition, the peaks appear several times during the cooling period. The maximum heat flow is considerably lower than that of the fired clay material used in this study even if considering the cooling rate is different.

This shows that supercooled water freezes much faster in the used fired clay material than in the cement pastes. The increase in the temperature during freezing also indicates that a large amount of latent heat was released in a short period of time. A possible reason for such a difference between cement pastes and fired clay materials is the pore structure. Fired clay materials generally have large pores of relatively uniform diameter as compared to cement-based materials $[12,13]$. It is possible that the difference in ice growth rates significantly affects the mechanical behaviour of the material.

Grübl and Sotkin [6] observed a similar change in temperature distribution in FT experiments using hardened cement paste. Their experiment shows temperature in the specimen rises rapidly at the same time in all measuring points during the freezing of the supercooled water.

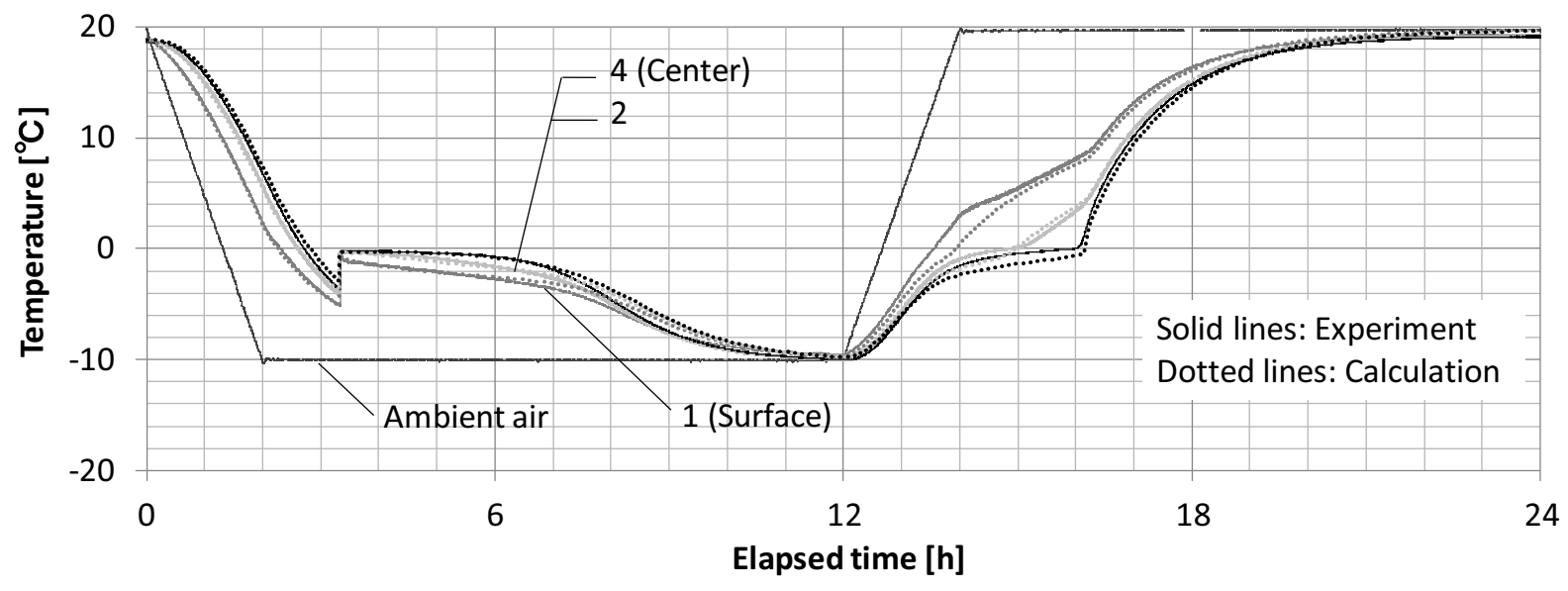

Fig. 11. Comparison of measured and calculated temperatures using a model with supercooling process 


\section{Conclusion}

In this paper, we reported the results of DSC and temperature distribution changes during the FT experiment. The results were used to characterise the supercooling effects of saturated fired clay materials. The DSC result shows that the freezing of the supercooled water in the fired clay material is considerably fast. In addition, a numerical model of the freezing and thawing process including the supercooling process was developed. The DSC result was used to calculate the water content increase rate in the basic equations. Although there was a large difference in specimen size between the DSC and FT experiment, the results of the numerical analysis using the DSC result agreed well with the temperatures measured in the FT experiment, confirming the validity of the model.

However, the freezing point of supercooled water and the growth rate of ice may vary depending on experimental conditions such as the rate of temperature change and the water content of the specimen. Therefore, further studies are necessary to clarify these issues. In addition, based on the detailed investigation of the freezing process of the supercooled water (e.g. [23]), it is necessary to examine more suitable methods to trigger freezing of the supercooled water in numerical analysis.

This work was supported by JSPS KAKENHI Grant Number JP17K06641 and JP19J10938. The authors would like to thank Enago (www.enago.jp) for the English language review.

\section{References}

1. S. Hokoi, M. Hatano, M. Matsumoto, M.K. Kumaran. J. Bldg. Phys. 24, 42-60 (2000)

2. X. Zhou, D. Derome, J. Carmeliet, Build. Environ. 125, 285-98 (2017)

3. G. Wardeh, B. Perrin, Constr. Build. Mater. 22, 60008 (2008)

4. M. Koniorczyk, D. Gawin, B.A. Schrefler, Comput. Methods Appl. Mech. Engrg. 297, 38-61 (2015)

5. G, Fagerlund, Mater. Struct. 6, 215-25 (1973)

6. P. Grübl, A. Sotkin, Cement Concrete Res. 10, 33345 (1980)

7. Q. Zeng, T. Fen-Chong, P. Dangla, K. Li, Int. J. Solids Struct. 48, 3267-73 (2011)

8. Q. Zeng, K. Li, T. Fen-Chong, J. Bldg. Phys. 40, 101-24 (2016)

9. D. Gawin, F. Pesavento, M. Koniorczyk, B.A. Schrefler, J. Bldg. Phys. 43, 1-38 (2019)

10. C. Iba, A. Ueda, S. Hokoi, Struct. Sur. 34, 135-49 (2016)

11. C. Feng, S. Roels, H. Janssen, Build. Environ. 164, 106343 (2019)

12. S. Diamond, Cement Concrete Res. 1, 531-45 (1971)

13. R.A. Cook, K.C. Hover, Cement Concrete Res. 29, 933-43 (1999)
14. H.L. Friedman, J. Polym. Sci. C6, 183-95 (1964)

15. M. Koniorczyk, P. Konca, Int. J. Therm. Sci. 122, 124-32 (2017)

16. M. Matsumoto, S. Hokoi, M. Hatano, Build. Environ. 36, 733-42 (2001)

17. B.L. Kurylyk, K. Watanabe, Adv. Water Resour. 60, 160-77 (2013)

18. A.Y. Uzan, Y. Kozak, Y. Korin, I. Harary, H. Mehling, G. Ziskind, Int. J. Heat Mass Tran. 106, 91-102 (2017)

19. K. Fukui, C. Iba, M. Taniguchi, K. Takahashi, D. Ogura, Investigation of thermal, moisture, and mechanical properties of wet and dry fired clay materials to assess frost damage risk, in the proceedings of the 4th Central European Symposium on Building Physics (CESBP 2019)

20. Kumaran M.K. Heat, air and moisture transfer in insulated envelope parts. Final Report Volume 3 Task 3: Material Properties (International Energy Agency ANNEX24, Laboratorium Bouwfysica, K.U. Leuven, 1996)

21. R.A. Shaw, A.J. Durant, Y. Mi, J. Phys. Chem. B 109, 9865-68 (2005)

22. M. Wu, K. Fridh, B. Johannesson, M. Geiker, Thermochim. Acta. 607, 30-38 (2015)

23. Y. Kishimoto, K. Takahashi, J. Environ. Eng. AIJ. 84, 135-42 (2019) [in Japanese] 